\title{
Dendritic cell
}

\section{GFP+ HIV - 1 VLP}

\section{Jurkat T cell}

Immune adaptor ADAP in T cells regulates HIV-1 transcription and cell-cell viral spread via different co-receptors

Wei et al. 


\title{
Immune adaptor ADAP in T cells regulates HIV-1 transcription and cell-cell viral spread via different co-receptors
}

\author{
Bin Wei ${ }^{1 \dagger}$, Lei Han ${ }^{1 \dagger}$, Truus E M Abbink ${ }^{2,7}$, Elisabetta Groppelli³ ${ }^{3}$ Daina Lim ${ }^{4}$, Youg Raj Thaker ${ }^{4}$, Wei Gao ${ }^{1}$, \\ Rongrong Zhai ${ }^{5}$, Jianhua Wang ${ }^{5}$, Andrew Lever ${ }^{2}$, Clare Jolly ${ }^{3}$, Hongyan Wang ${ }^{1,4^{*}}$ and Christopher E Rudd ${ }^{4,6^{*}}$
}

\begin{abstract}
Background: Immune cell adaptor protein ADAP (adhesion and degranulation-promoting adaptor protein) mediates aspects of T-cell adhesion and proliferation. Despite this, a connection between ADAP and infection by the HIV-1 (human immunodeficiency virus-1) has not been explored.

Results: In this paper, we show for the first time that ADAP and its binding to SLP-76 (SH2 domain-containing leukocyte protein of $76 \mathrm{kDa}$ ) regulate HIV-1 infection via two distinct mechanisms and co-receptors. siRNA downregulation of ADAP, or expression of a mutant that is defective in associating to its binding partner SLP-76 (termed M12), inhibited the propagation of HIV-1 in T-cell lines and primary human T-cells. In one step, ADAP and its binding to SLP-76 were needed for the activation of NF-KB and its transcription of the HIV-1 long terminal repeat (LTR) in cooperation with ligation of co-receptor CD28, but not LFA-1. In a second step, the ADAP-SLP-76 module cooperated with LFA-1 to regulate conjugate formation between T-cells and dendritic cells or other T-cells as well as the development of the virological synapse (VS) and viral spread between immune cells.
\end{abstract}

Conclusions: These findings indicate that ADAP regulates two steps of HIV-1 infection cooperatively with two distinct receptors, and as such, serves as a new potential target in the blockade of HIV-1 infection.

Keywords: ADAP, HIV-1 transcription, HIV-1 transmission, Integrin, Virological synapse

\section{Background}

Infection with the human immunodeficiency virus-1 (HIV-1) causes a severe and selective depletion of $\mathrm{CD}_{4}^{+}$ $\mathrm{T}$ lymphocytes in the immune system [1,2]. HIV-1 binds primarily to $\mathrm{CD} 4$ together with chemokine receptors CXCR4 or CCR5. Receptor engagement induces a conformational change in the HIV envelope glycoprotein (Env), which mediates membrane fusion and viral penetration. Replication of HIV-1 is mediated primarily by transcription factors such as NFAT, AP1 and NF- $\kappa B[3,4]$. NF- $\kappa B$ regulates long terminal

\footnotetext{
*Correspondence: hongyanwang@sibcb.ac.cn; cer51@cam.ac.uk

${ }^{\dagger}$ Equal contributors

'The State Key Laboratory of Cell Biology, Institute of Biochemistry and Cell Biology, Shanghai Institutes for Biological Sciences, Chinese Academy of Sciences, Shanghai, China

${ }^{6}$ Cambridge Institute of Medical Research, Hills Road, CB2 OXY, Cambridge, UK

Full list of author information is available at the end of the article
}

repeat (LTR) activation within the HIV-1 genome by interacting with tandem binding sites in the enhancer region and mutant IкB alpha inhibits de novo HIV-1 infection in T cells [5-7]. Mutations within internal TATA sequences or the NF-kB binding sites also impair LTR activity and viral replication [8].

HIV-1 can disseminate between immune cells either by cell-free infection or by direct cell-cell spread. Cellcell transmission of HIV-1 takes place through membrane nanotubes or virological synapses (VS) that form following physical contact between infected and uninfected cells [9-13]. Electron micrographs have shown HIV-1 accumulation at the interface between HIV-1 infected and uninfected cells [11,14], while immunofluorescence microscopy and time-lapse imaging have shown the accumulation of viral proteins at the contact interface as well as the movement of viruses from one cell to another [11,15-17]. This mode of dissemination

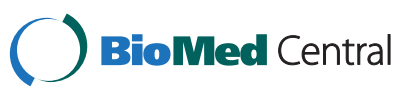

(c) 2013 Wei et al.; licensee BioMed Central Ltd. This is an Open Access article distributed under the terms of the Creative Commons Attribution License (http://creativecommons.org/licenses/by/2.0), which permits unrestricted use, distribution, and reproduction in any medium, provided the original work is properly cited. 
is at least 500 -fold more efficient than infection by cell-free virus $[10,16,17]$, which may facilitate HIV-1 spread within secondary lymphoid tissues [18]. Further, infected dendritic cells (DCs) and macrophages use the VS to transfer HIV-1 to T cells $[19,20]$. Spread via synapses requires the localization of CD4, CXCR4 or CCR5 as well as the integrin lymphocyte functionassociate antigen 1 (LFA-1) and intercellular adhesion molecule-1 (ICAM-1) at the site of cell-cell contact [10-13,17,20]. The blockade of LFA-1 reduces VS formation [12], and more importantly, DCs isolated from leukocyte adhesion deficiency (LAD)-I patients show decreased viral spreading to $\mathrm{CD} 4^{+}$T-cells [21]. Furthermore, LFA-1 and ICAM-1 from host cells can be incorporated into HIV particles for enhanced infectivity $[22,23]$.

The activation status of T-cells plays an important role in facilitating viral replication and spread since HIV-1 replicates inefficiently in quiescent $T$ cells [24]. In this context, immune cell specific adaptor proteins that mediate $\mathrm{T}$-cell activation and effector functions have been identified $[25,26]$. These adaptors lack definable catalytic activities, but instead, possess binding domains or sites for the formation of multimeric complexes. Of these, Linker of activated T cells (LAT) and Src homology 2 (SH2) domain-containing leukocyte protein of $76 \mathrm{kDa}$ (SLP-76) (also named lcp2, lymphocyte cytosolic protein 2) are needed for antigen-receptor induced calcium mobilization $[27,28]$. SLP-76 binds to ADAP (adhesion- and degranulation-promoting adaptor protein, also named as Fyb [fyn binding protein] or SLAP130 [SLP-76-associated phosphoprotein of $130 \mathrm{kDa}$ ]), which is needed for up-regulation of LFA-1 adhesion [29-31]. This pathway is mediated downstream by SKAP1 (Src kinase-associated phosphoprotein 1) that regulates the complex formation between Rap1 and RapL (regulator for cell adhesion and polarization enriched in lymphoid tissues) [26,32-36]. Two tyrosine motifs at $\mathrm{Y}^{595} \mathrm{DDV}$ and $\mathrm{Y}^{651} \mathrm{DDV}$ of ADAP bind to the SH2 domain of SLP-76 upon TCR stimulation. A double point mutation in ADAP at $\mathrm{Y}^{595} \mathrm{~F}$ and $\mathrm{Y}^{651} \mathrm{~F}$ (termed M12) is defective in SLP-76 binding and shows reduced LFA- 1 adhesion and PSMAC formation [31,34]. Despite this, a potential connection between ADAP and HIV-1 infection has not been explored.

In this study, we demonstrate that ADAP and its binding to SLP-76 regulate two steps of HIV-1 infection by cooperating differentially with two distinct co-receptors. Loss of ADAP and the SLP-76/ADAP module markedly impaired CD28-mediated HIV-1 transcription as well as LFA-1-dependent formation of virological synapse for cell-cell viral spread. These findings identify ADAP and its signaling module as key regulators of HIV-1 infection.

\section{Results}

Disruption the SLP-76-ADAP signaling module inhibits HIV-1 infection

We and others have previously outlined the importance of the SLP-76-ADAP-SKAP1 pathway in the activation of LFA-1 [31-36]. A mutant of ADAP lacking tyrosine residues 595 and 651 (termed M12) is unable to bind to SLP76 and impairs LFA-1 activation [31,34]. We assessed whether wild-type ADAP and the mutant M12 could regulate HIV-1 infection in Jurkat T-cells (Figure 1A,B). Jurkat T-cells were stably transduced with retroviral supernatants encoding ADAP-IRES-GFP or M12-IRES-GFP (termed JK-ADAP/GFP and JK-M12/GFP) or with GFP alone (JK-GFP). Expression remained stable due to integration. The transfectants showed the same expression levels of CD4, CXCR4, CD3, CD28, $\beta 1$ and $\beta 2$ integrins as the control GFP expressing Jurkat cells as measured by flow cytometry (Figure 1B). We next infected these cells with a single-cycle HIV-1 virus carrying a luciferase reporter (equivalent to $5 \mathrm{ng} \mathrm{p} 24^{\mathrm{Gag}}$ ). The mRNA levels of HIV-1 gag were measured at 72 hours post-infection by quantitative RT-PCR (qRT-PCR) with specific primers for HIV-1 gag. JK-ADAP/GFP cells showed 3-4-fold higher levels of HIV-1 gag mRNA when compared to JK-GFP cells. By contrast, JK-M12/GFP cells failed to support the increase of HIV-1 gag mRNA beyond that observed in the JK-GFP cells (Figure 1A). The level of transfected M12 was similar to ADAP as seen by western blotting (Figure 1A, upper right inset). We confirmed that after HIV-1 infection, overexpression of ADAP/GFP or M12/ GFP had no effects on CD4 or CXCR4 expression in Jurkat cells (Additional file 1: Figure S1A).

We next stably overexpressed GFP, ADAP or M12 into human C8166 T cells (C8166-GFP, C8166-ADAP and C8166-M12) (Additional file 1: Figure S1B). These cells were infected with low dose or high dose of HIV-1 (equivalent to 1.5 or $15 \mathrm{ng} \mathrm{p} 24^{\mathrm{Gag}}$, respectively). Supernatants were collected and quantified by ELISA for levels of of HIV-1 p24 ${ }^{\mathrm{Gag}}$ at various times post-infection. We found that at both doses of input virus, C8166-M12 cells were impaired in their support of HIV-1 replication relative to cells expressing wild-type ADAP. When we used low dose of virus to infect cells, C8166-ADAP cells and the control cells supported productive infection, whereas C8166-M12 cells failed to produce the detectable levels of $\mathrm{p} 24^{\mathrm{Gag}}$ (Additional file 1: Figure S1B, right panel). Over $95 \%$ of C8166 T cells overexpressed GFP, or ADAP/GFP or M12/ GFP (Additional file 1: Figure S1B, left and middle panels), which had no effect on the expression of surface receptors (Additional file 1: Figure S1C) and showed similar growth rates (Additional file 1: Figure S1D). We further examined whether HIV-1 infection of human primary $\mathrm{CD} 4^{+} \mathrm{T}$ cells was dependent on ADAP (Figure 1C,D). ADAP expression was reduced using specific siRNAs. qRT-PCR showed a 


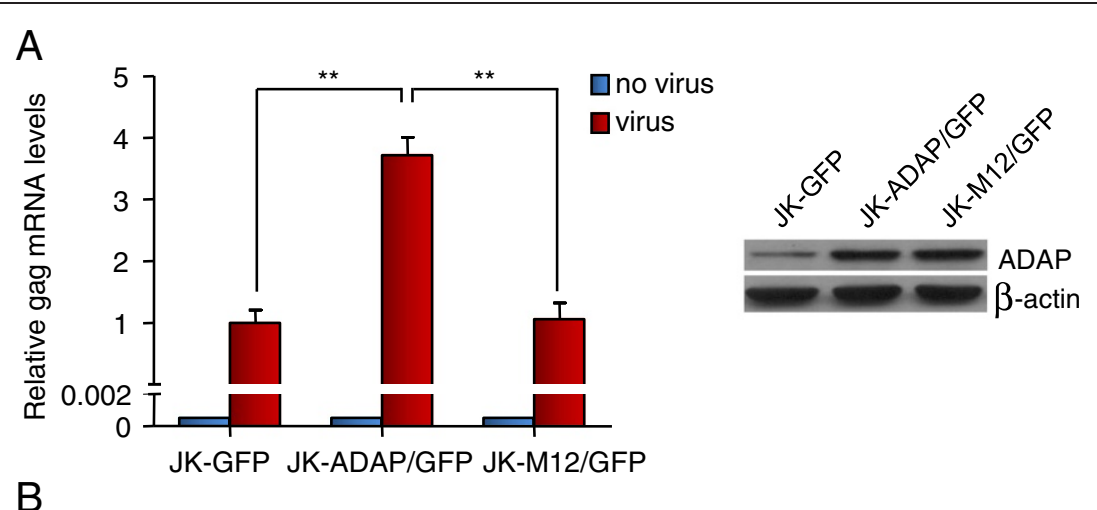

B
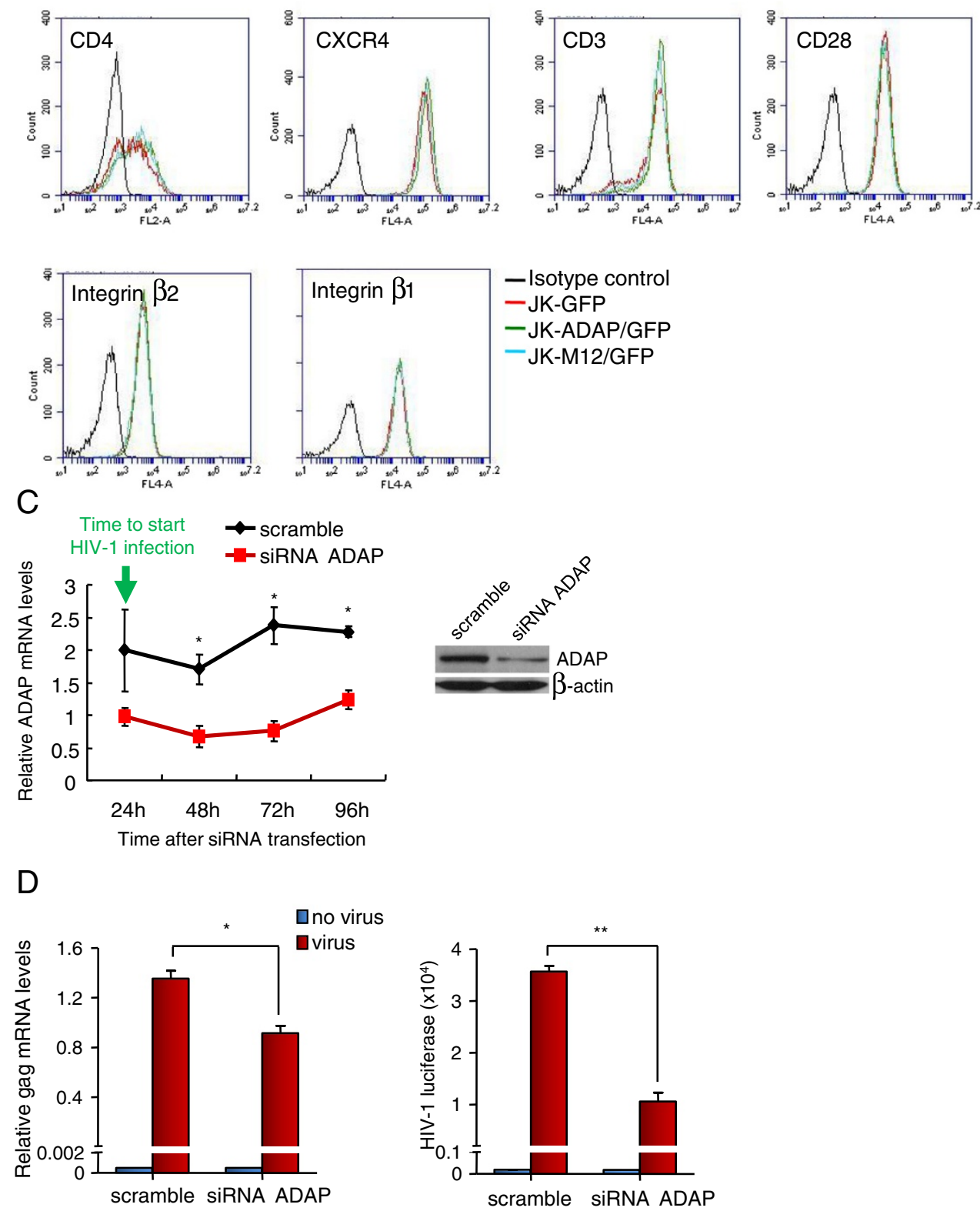

Figure 1 (See legend on next page.) 
(See figure on previous page.)

Figure 1 Disruption the SLP-76-ADAP signaling module inhibits HIV-1 infection in T-cells. (A) Jurkat T cells were stably transfected with GFP, ADAP/GFP or M12/GFP and infected with single-cycle luciferase reporter HIV-1 (equivalent to $5 \mathrm{ng} \mathrm{p} 24^{\mathrm{Gag}} / 10^{6}$ cells). The HIV- 1 gag mRNA levels were determined by $q R T-P C R 72$ hrs post infection $(P=0.032$, left and $P=0.005$, right). The ADAP/M12 expression levels were examined by immunoblotting. (B) Overexpression of ADAP/GFP or M12/GFP in Jurkat cells did not alter the surface expression levels of CD4, CXCR4, CD3, CD28, $\beta 1$ or $\beta 2$ integrins as determined by flow cytometry. (C) Human primary CD4 ${ }^{+} T$ cells were transfected with the scramble siRNA or siRNA targeting ADAP, and the knockdown efficiency was confirmed by immunoblotting (48 hrs post-transfection) or by qRT-PCR at different time points during HIV-1 infection. (D) Human primary $\mathrm{CD}^{+} \mathrm{T}$ cells were transfected with siRNAs for $24 \mathrm{hrs}$, then infected with single-cycle luciferase reporter HIV-1. The HIV-1 gag mRNA levels were determined by qRT-PCR 72 hrs post infection (left panel, $P=0.0192$ ). Alternatively, the amount of HIV-1 was measured according to the luciferase readings (right panel, $P=0.0032$ ) (* represents $p=<0.05$, ** represents $p=<0.01$ ).

$50-60 \%$ reduction in ADAP mRNA transcripts over a period of 96 hours post-transfection (Figure 1C). Similarly, western blotting of cells at 48 hours confirmed the significantly reduced ADAP expression after transfection with siRNA-ADAP (Figure 1C, right inset). siRNA transfected human $\mathrm{CD}^{+} \mathrm{T}$ cells were then infected with the singlecycle HIV-1 virus containing luciferase reporter [12]. siRNA for ADAP reduced HIV-1 gag mRNA levels by $30 \%$ when assessed at 72 hours post-infection (Figure 1D, left panel). A measurement of luciferase activity confirmed that siRNA for ADAP resulted in a significant reduction of HIV-1 infection (Figure 1D, right panel). The surface expression of CD3, CD4, CD28, CXCR4, $\beta 1 / \beta 2$ integrins and ICAM-1 in human $\mathrm{CD}^{+}{ }^{+} \mathrm{T}$ cells was not affected by knockdown of ADAP (Additional file 1: Figure S1E). Collectively, these data indicate that ADAP is needed for the optimal HIV-1 infection of T-cell lines and primary human T-cells.

\section{ADAP and SLP-76 regulates HIV-1 LTR transcription in a CD28- and NF-KB-dependent manner}

To uncover the molecular basis of ADAP involvement in $\mathrm{HIV}-1$ infection, we firstly examined its potential effects on the induction of HIV-1 LTR transcription. Wild type, SLP-76-deficient Jurkat T-cells (termed J14) or ADAP-deficient Jurkat T-cells (termed JDAP) [37] were transfected with a pLTR-gag3-flag-luc reporter plasmid followed by stimulation via anti-CD3/CD28 ligation for 6 hours. The pLTR-gag3-flag-luc plasmid contains the HIV-1 5' LTR promoter region with two NF-kB binding sites and a firefly luciferase open reading frame [38]. HIV-1 transcription was then assessed by a measure of luciferase activity (Figure 2A). Anti-CD3/CD28 stimulation induced a two-fold increase in $\mathrm{HIV}-1$ transcription in wild type Jurkat cells, an effect that was not seen in J14 cells (Figure 2A, upper left panel). Re-expression of SLP-76 into J14 cells restored and enhanced HIV-1 transcription (blue bars). Similarly, anti-CD3/CD28 induced HIV-1 transcription was markedly impaired in ADAPdeficient JDAP cells (Figure 2A, upper right panel). Furthermore, the overexpression of SLP-76 in JDAP cells did not bypass or compensate for the ADAP deficiency (Figure 2A, lower panel). Anti-CD3/CD28 increased NF- $\mathrm{kB}$ binding by over 3 -fold in wild type Jurkat cells as measured by an electrophoretic mobility shift assay (EMSA) (the integrated OD values from Gel-Pro image analysis software: 136 to 450), but not in JDAP cells (Figure 2B, left panel). In agreement with this, a difference in the degradation of $I_{\kappa} B$ alpha was observed between wild type and JDAP cells (Figure 2B, right panel). I $\mathrm{kB}$ alpha is an inhibitor of NF-kB which is degraded in response to TCR/CD28 ligation [39]. AntiCD3/CD28 induced a degradation of IKB alpha in Jurkat cells over a period of 90-120 min, an effect that was not observed in JDAP cells. Instead, JDAP cells sustained I $\mathrm{B}$ alpha expression over the time course. These observations indicate that ADAP expression is needed for anti-CD3/CD28 induced NF- $\mathrm{kB}$ activation.

We also assessed the effect of ADAP binding to SLP-76 to regulate $\mathrm{HIV}-1$ transcription by using cells transfected with wild type ADAP or the mutant M12 (Figure 2C). ADAP expression increased anti-CD3/CD28 induced transcription of the HIV-1 LTR by 2.5 fold, while this was impaired with M12 (i.e. 30-40 percent less than observed for ADAP, Figure 2C, left panel). ADAP overexpression also increased HIV-1 transcription in response to antiCD3 and CD80-Fc, the natural ligand for CD28 (Figure 2C, right panel). Further, an EMSA assay showed that ADAP increased NF- $\mathrm{kB}$ activation (OD values from 11 to 68 ), and this increase was blocked by M12 (OD values from 16 to 24) (Figure 2C, middle panel). As a control, ADAP could not further enhance the activity of a HIV-luciferase reporter lacking NF- $\mathrm{B}$ binding sites (Additional file 2: Figure S2A). Significantly, the same inhibitory effect of M12 was noted in primary human T-cells that had been co-transfected with pLTR-gag3-flag-luc and ligated with anti-CD3/CD28. ADAP expression increased HIV transcription by $2.5-3$ fold, whereas M12 had no effect (Figure 2D). These data indicate that ADAP and its binding to SLP-76 cooperate with CD28 co-ligation to regulate LTR activity in Jurkat and human primary T-cells.

Stimulation of T-cells from CD28 deficient Jurkat cells further showed a dependency of the NF-kB-driven HIV1 transcriptional response on CD28 (Figure 2E, left panel). Anti-LFA-1 antibody (i.e. anti-CD18) ligation had no ability to activate HIV-1 transcription alone, or in conjunction with CD3/CD28 ligation or ADAP/GFP expression (right panel). These data indicate that CD28, 


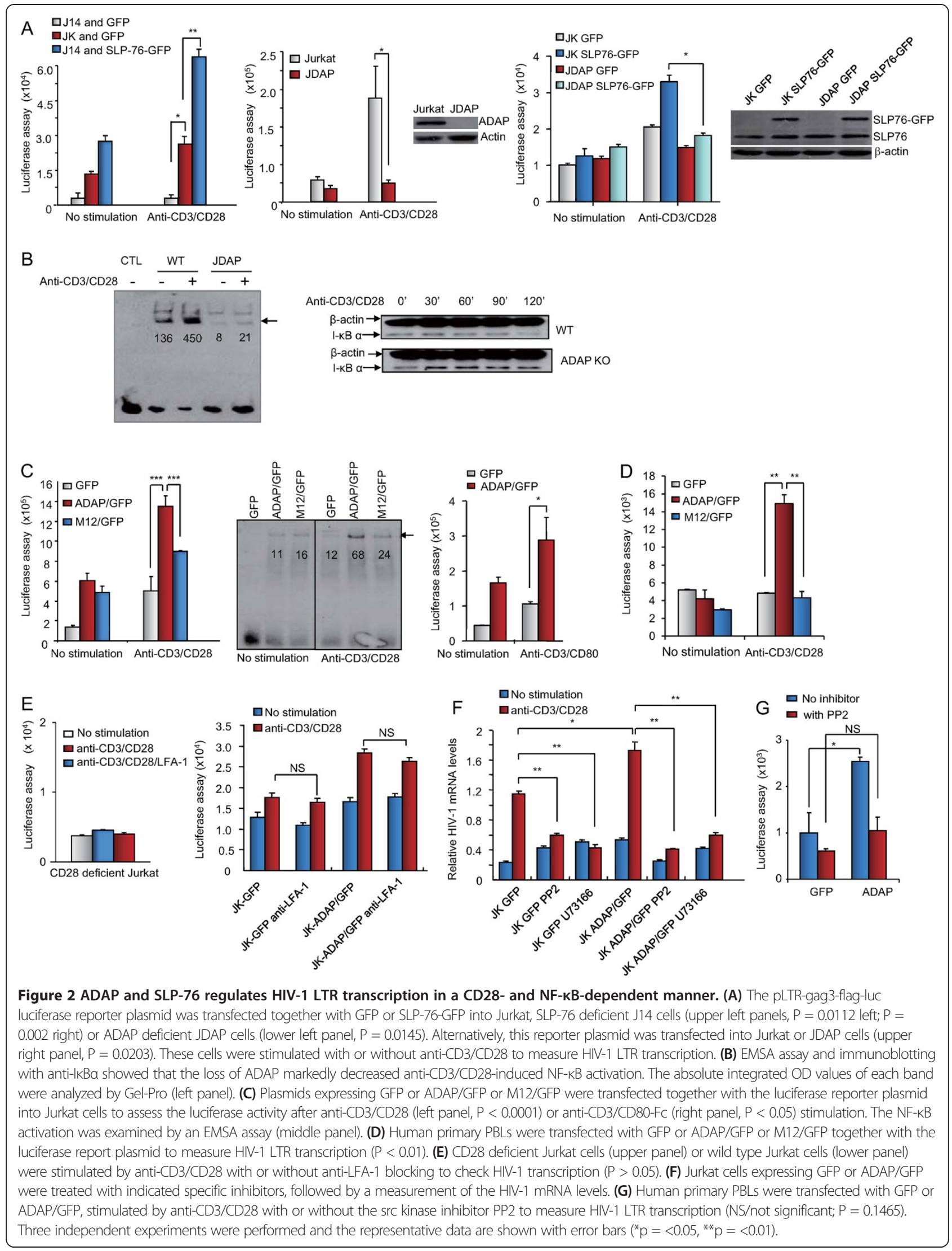


but not LFA-1 costimulation, cooperates with ADAP in the activation of HIV-1 transcription.

We next determined whether ADAP activation of the HIV-1 LTR intersects with other signaling events. Specific inhibitors of src kinases, phosphotidylinositol 3 kinase (PI $3 \mathrm{~K}$ ) and phospholipase C (PLC) were used in conjunction with anti-CD3/CD28 stimulation. We measured the HIV-1 gag mRNA levels by qRT-PCR (Figure 2F) or HIV 5' LTR transcription activity (Additional file 2: Figure S2B). Src kinase inhibitor PP2 and PLC inhibitor U73122 significantly decreased anti-CD3/CD28 induced HIV-1 transcription in Jurkat cells, and reduced the increase observed in ADAP/GFP expressing cells. The inhibitory effect of PP2 on HIV-1 transcription was also observed in primary human T-cells (Figure 2G), showing that ADAP expression increased anti-CD3/CD28 induced transcription by 2.5 -fold, which was blocked by PP2 treatment. The PI $3 \mathrm{~K}$ inhibitor LY294002 however did not affect transcription (Additional file 2: Figure S2B). We previously showed that this concentration of LY294002 effectively inhibited PI $3 \mathrm{~K}$ in Jurkat cells by examining protein kinase $\mathrm{B}$ (AKT/PKB) phosphorylation [40]. These data indicate that src kinases and PLC are needed for ADAP enhancement of antiCD3/CD28 induced HIV-1 transcription.

\section{LFA-1 dependency in ADAP-induced HIV-1 infection}

The striking effects of M12 on HIV-1 replication suggested that additional mechanisms might also be operating. Of particular interest was the involvement of ADAP on the activation of LFA-1 for adhesion [31,34]. To assess the dependency on ADAP-induced LFA-1 adhesion during HIV-1 infection, single-cycle HIV-1 containing a luciferase reporter was incubated with C8166 cells expressing GFP control, ADAP/GFP or M12/GFP. These cells were either left untreated, or incubated with virus in the absence or presence of soluble ICAM-1-Fc or anti-LFA-1 to block LFA-1 -mediated adhesion (Figure 3A). HIV-1 gag mRNA levels were assessed using qRT-PCR with specific primers for HIV-1 gag (Figure 3A, left panel). Gag mRNA levels were reduced in the control/GFP (i.e. from 0.7 to $0.3, \mathrm{p} \leq 0.05$ ) and ADAP/GFP cells (i.e. from 1.4 to $0.3, \mathrm{p} \leq 0.01$ ) in the presence of soluble ICAM-1-Fc treatment. In contrast, the already impaired levels of HIV-1 gag mRNA production in M12/GFP cells (i.e. 1.4 vs. 0.35 when compared to ADAP/ GFP cells, $\mathrm{p} \leq 0.01$ ) was not further reduced by the presence of ICAM-1-Fc. Similar to the blocking effect by soluble ICAM-1-Fc, anti-LFA-1 antibody also impaired HIV-1 gag mRNA production (Figure 3A, left panel). We also measured the luciferase reading from the single-cycle luciferase reporter HIV-1-infected cells, where soluble ICAM-1-Fc or anti-LFA-1 treatment reduced luciferase readings in the controls and ADAP/GFP expressing C8166 cells (Figure 3A, right panel). Consistently, the decreased luciferase reading in M12/GFP cells was not further reduced by soluble ICAM-1-Fc or anti-LFA-1 treatment (Figure 3A, right panel). As a control, flow cytometry confirmed that ADAP and M12 did not alter LFA-1 expression (Figure 3B). In addition, using higher levels of HIV-1 particles (5 ng p24 ${ }^{\mathrm{Gag}}$ ), ADAP expression enhanced the luciferase values relative to the GFP transfected control, while M12 markedly decreased the amount of viruses). Consistent results were also observed when these cells were incubated with lower quantities of virus (1 ng p24 ${ }^{\text {Gag }}$ ) (Figure 3C). These data indicate that the SLP-76-ADAP module regulates HIV-1 infection in an LFA-1-dependent manner.

\section{SLP-76-ADAP regulates the VS formation between T-cells and DCs}

The blockade of ADAP-induced HIV-1 infection with soluble ICAM-1-Fc suggested that ADAP might contribute to integrin-mediated viral transmission via affecting the formation of VS and cell-cell conjugation. LFA-1 adhesion is known to modulate T-cell conjugation with dendritic cells (DCs) or T-cells, even in an antigen independent manner; and T-cells or DCs expressing HIV-1 can spread the virus by forming conjugates with non-infected T-cells [11-16]. We therefore investigated whether ADAP and SLP-76 could regulate conjugation between DCs and non-infected T cells. For this, Jurkat, JDAP and J14 cells were incubated for 1 hour with mature human DCs that were pre-pulsed with HIV-1-gag-GFP, followed by the scoring of closely opposed pairs of HIV1-gag-GFP expressing DCs and T-cells. Examples of HIV-1-gag-GFP-pulsed DCs and anti-ADAP stained T-cells are shown (Figure 4A). HIV-1-gag-GFP in DCs and ADAP in T-cells localized at the contact region between cells. Our previous reports have demonstrated that M12 disrupted its binding with SLP-76, and reduced LFA-1 -mediated conjugates formation between antigen presenting cells and T cells $[31,34]$. We asked whether the mutant M12 could impair DC-T conjugation and virological synapse formation. Jurkat $\mathrm{T}$ cells stably overexpressing GFP, ADAP/ GFP or M12/GFP were incubated with mature human DCs that were pre-pulsed with HIV-1-gag-GFP (Figure 4B). ADAP expression enhanced conjugate formation between DC and T cells (64\% vs. $47 \%$ compared to vector controls, $\mathrm{p} \leq 0.05)$. By contrast, M12 expression significantly decreased conjugation ( $64 \%$ vs. $38 \%, \mathrm{p} \leq 0.01)$. Notably, ADAP also enhanced the formation of VS as defined by the presence of HIV-1 at the interface ( $65 \%$ vs. $49 \%, \mathrm{p} \leq 0.05)$, while M12 expression reduced VS formation to $39 \%$ ( $\leq \leq 0.01$ ). In the case of vector and ADAP transfected cells, LFA-1 and HIV-1 co-localized at the interface (Figure 4B, right panels).

Further, similar results were seen in comparing conjugation of Jurkat relative to JDAP cells (Figure 4C). JDAP cells formed significantly fewer conjugates than Jurkat cells (i.e. from $37 \%$ to $22 \%$; $\mathrm{p} \leq 0.01$ ). J14 also blocked the conjugate formation with infected DCs to a similar 


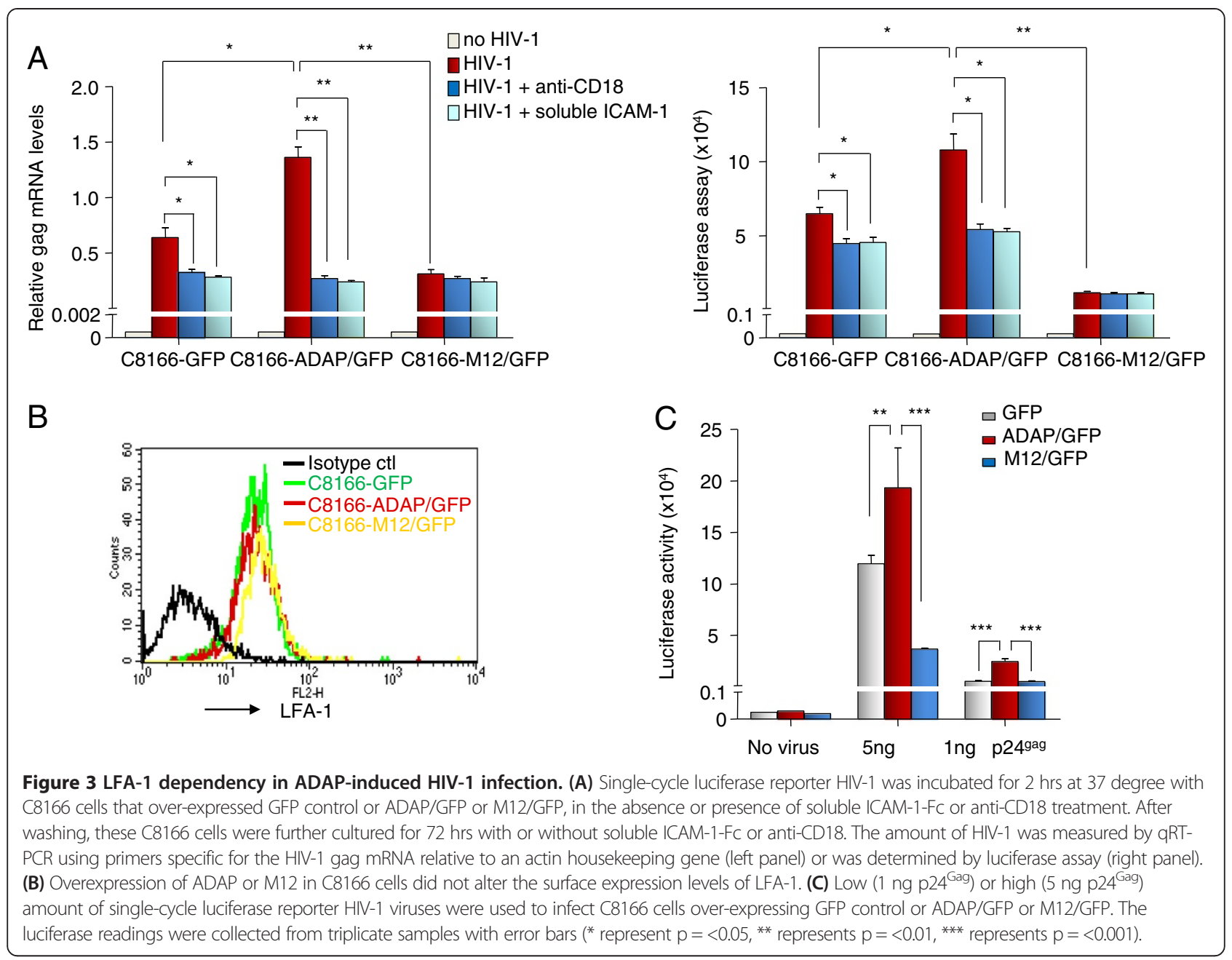

degree (Figure 4C). Further, amongst the cells that formed conjugates, HIV-1-gag-GFP localization was reduced at the contact region when DCs contacted with JDAP cells or J14 cells (Figure 4C). While $46 \%$ of wildtype T-cells showed HIV-1-gag-GFP localization at the VS, only $15 \%$ of the JDAP or J14 cells showed this feature (Figure 4C). As noted, deficiency of ADAP in JDAP cells (Figure 1B) or deficiency of SLP-76 in J14 cells (Additional file 3: Figure S3A) did not affect LFA-1 expression. Next, we confirmed that knockdown of ADAP in human primary $\mathrm{CD}^{+} \mathrm{T}$ cells decreased both conjugate formation (from $41 \%$ to $27 \%, \mathrm{p} \leq 0.05$ ) and VS formation (from 53\% to $31 \%, \mathrm{p} \leq 0.01$ ) (Figure $4 \mathrm{D})$. Taken together, these data indicate that the loss of ADAP or SLP-76 or disruption of the binding between SLP-76 and ADAP impairs conjugation and VS formation between T-cells and DCs.

\section{The SLP-76-ADAP module regulates viral transfer} between T-cells

To assess viral-infected T-cells conjugation with noninfected T-cells, ADAP or M12 expressing target T cells (i.e. GFP positive) were incubated with $\mathrm{HIV}^{+}$donor $\mathrm{T}$ cells infected with a CXCR4-tropic HIV-1 virus isolate (pNL43). Conjugates were allowed to form for 1 hour with a human non-inhibitory anti-HIV Env monoclonal antibody to stain surface Env (blue), while HIV-1 Gag p17 and p24 were intracellular stained (red) (Figure 5A). Conjugates were scored as apposed pairs consisting of one $\mathrm{GFP}^{+}$target cell and a HIV Gag ${ }^{+}$donor cell. Examples of a conjugate with the GFP labeled T-cell (panel a), Env staining (panel b), anti-Gag staining (panel c) and the merged image (panel d) are shown (Figure 5A, left panels). While ADAP supported the formation of conjugates amongst $65 \%$ of the cells, M12 reduced this to $38 \%(\mathrm{p}=0.02)$ (Figure 5A, middle panel). Amongst the remaining cells that formed conjugates, a similar number of ADAP or M12 expressing cells formed a detectable VS region (Figure 5A, right panel). However, a significant difference was noted in the size of the VS interface formed between viral-infected $\mathrm{T}$ cells with ADAP or M12 expressing target cells (Figure 5B, $\mathrm{p}=<0.001$ ). While ADAP expressing cells showed an 
A

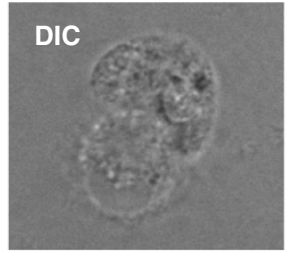

\section{HIV-1}

.
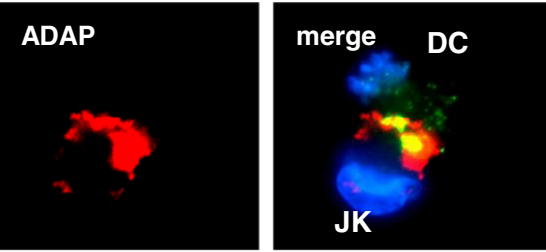

B
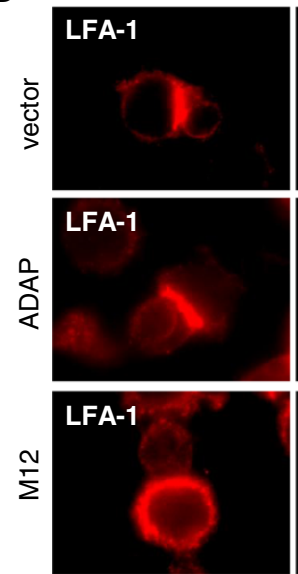

C

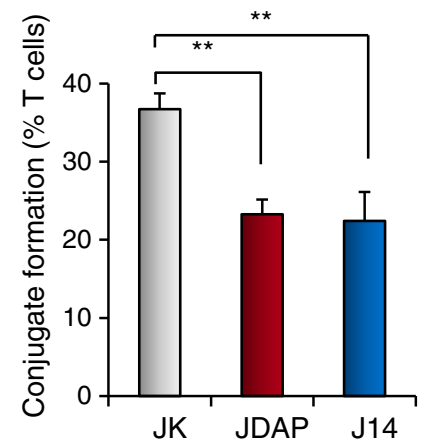

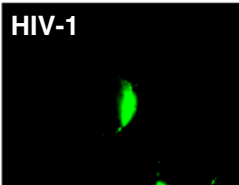
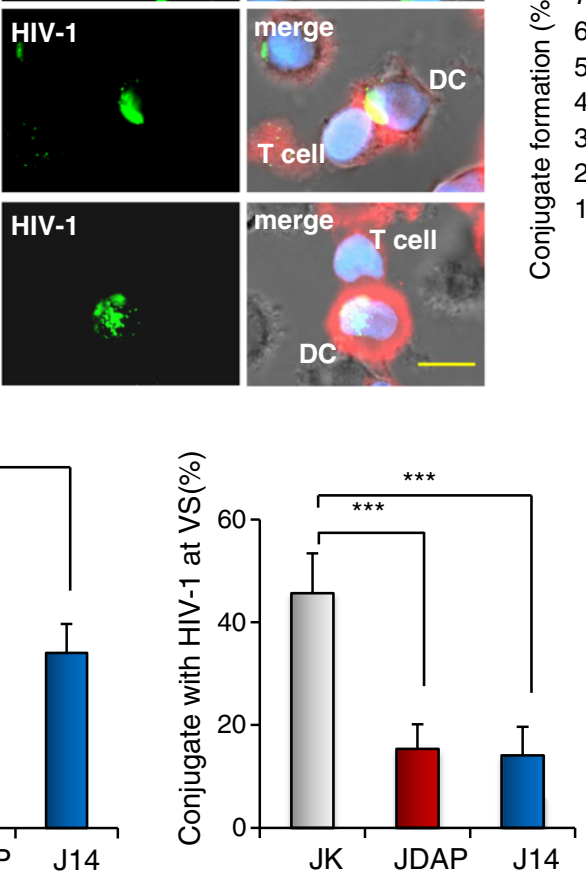
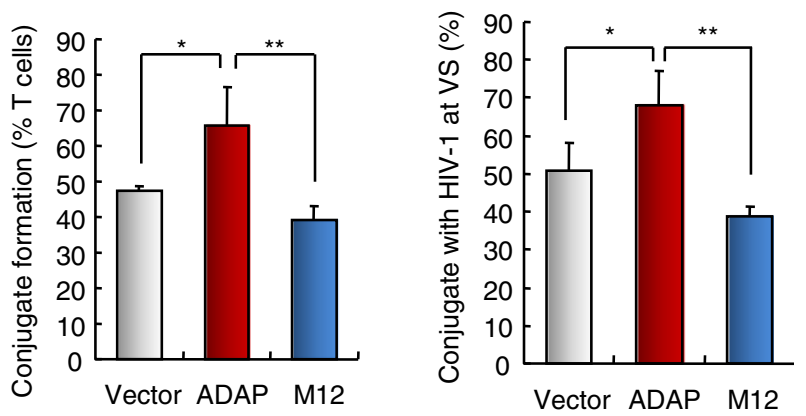

D

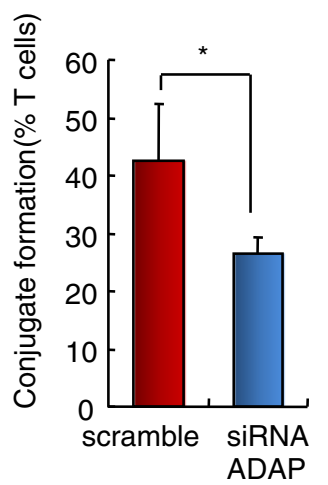

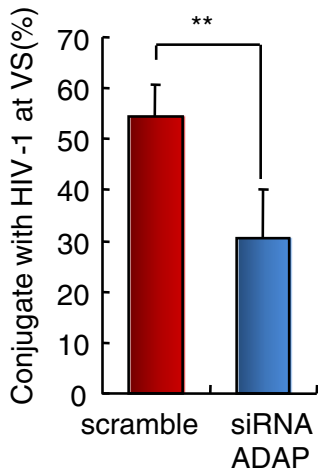

Figure 4 SLP-76-ADAP regulates the VS formation between T-cells and HIV-1-pulsed DCs. Jurkat, JDAP or J14 cells were incubated for 30 min with mature human DCs that were pre-pulsed with HIV1-gag-GFP VLPS. Conjugate formation and the presence of HIV1-gag-GFP at the VS interface was assessed. (A) Example of a conjugate shows that anti-ADAP staining in T-cells and HIV1-gag-GFP VLPS in DCs were peaked at the interface between DC and T cell. (B) Jurkat cells stably overexpressing GFP, ADAP/GFP or M12/GFP were incubated for 30 min with HIV1-gag-GFPpulsed human DCs. Represent examples are shown in right panels. Histograms show the percent of conjugate formation (left panel; $P=0.0198$ left, $P=0.0068$ right) and colocalization of HIV1-gag-GFP and LFA-1 at the VS (right panel; $P=0.0107$ left, $P=0.0022$ right). (C) Deficiency of ADAP (JDAP) or deficiency of SLP-76 (J14) impaired HIV1-gag-GFP and LFA-1 localization at the interface between Jurkat cells and DCs. Histograms show the percent of conjugate formation (upper panel, $\mathrm{P}=0.0011$ left, $\mathrm{P}=0.043$ right) or colocalization of HIV1-gag-GFP with LFA-1 at the VS (lower panel, $\mathrm{P}=0.0006$ ). (D) Human primary CD4 ${ }^{+}$T cells were transfected with the scramble siRNA or siRNA ADAP for 48 Hrs, which were then incubated for 30 min with mature human DCs pre-pulsed with HIV1-gag-GFP VLPs. The conjugate formation $(P=0.0241)$ and HIV1-gag-GFP at the VS interface ( $P=0.0018)$ were analyzed and showed in histograms. Typical examples were shown in right panel. Typical examples are shown in right panel ${ }^{*}$ represents $p=<0.05$, ** represents $p=<0.01$, ${ }^{* *}$ represents $p=<0.001$ ).

average contact site of 6.4 units, M12 conjugates reduced this to 4.1 units (Figure 5B). In agreement with this, the loss of ADAP dramatically inhibited anti-CD3 and ICAM-1- induced cell spreading (Additional file 3: Figure S3B).
To assess the effect of ADAP and M12 on HIV-1 transmission between $T$ cells, we next quantified cell-cell spread using a well-defined qRT-PCR assay in which the copy number of HIV-1 pol gene was measured and enumerated relative to an albumin housekeeping gene 


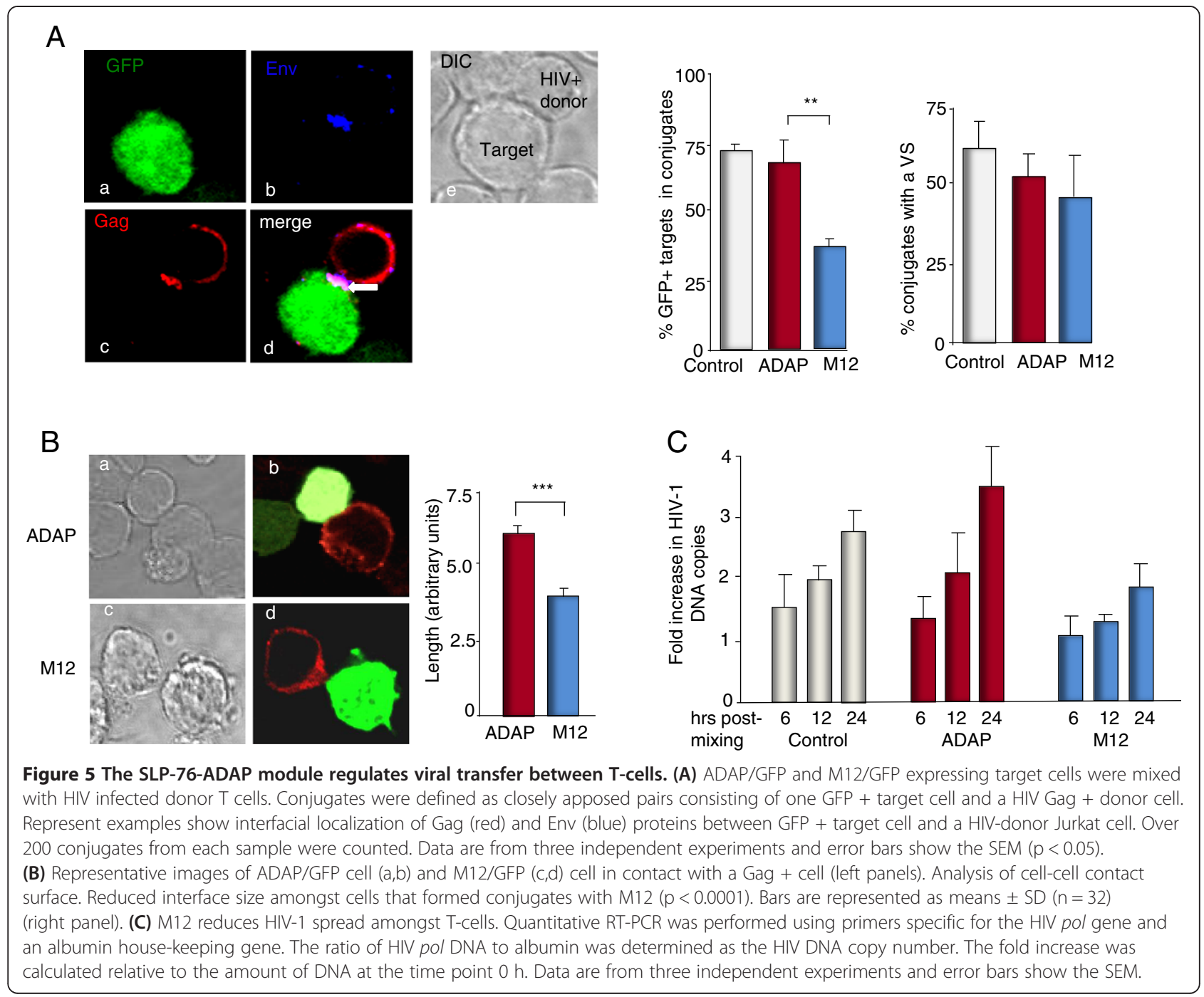

(Figure 5C) $[10,13,14]$. The fold increase was calculated relative to the number of DNA copies at time point 0 hour to account for the presence of integrated proviral DNA within the infected donor cell population. HIV pol copy number corresponds to de novo HIV-1 DNA synthesis. An increase above 1 reflects reverse transcription as a result of cell-to-cell spread and new infection of the target cells. While the presence of ADAP sustained cellto-cell spread, M12 expression induced a significant reduction in viral transfer between cells (i.e. 3.5 vs. 2.2). Overall, these data indicate that M12 effectively reduces the number of T-T cell conjugates and the size of the VS, leading to reduced HIV-1 viral transmission.

\section{Discussion}

Although ADAP acts as an important mediator of T-cell signaling and function [29-32,34,37,41], its role in HIV-1 infection of T-cells had yet to be explored. In this study, we showed that ADAP was a potent regulator of two central events needed for HIV-1 infection, namely, the HIV-1 LTR transcription and viral transfer at the synapses of T-T or DC-T conjugates. Further, the two functions were regulated by two different co-receptors, CD28 in the case of HIV-1 transcription, and LFA-1 in the case of cell-cell transmission. Expression of M12 or the down-regulation of ADAP by siRNA effectively suppressed the propagation of HIV-1. Our findings therefore identify ADAP and the SLP-76/ADAP signaling module as new potential targets for the repression of HIV-1 infection.

Our studies have demonstrated that ADAP regulates two distinct events during HIV-1 infection of T-cells. While NF- $\mathrm{kB}$ drives the replication of the long terminal repeat (LTR) [5], the identity of the full range of upstream regulators of NF-kB-LTR is unknown. A variety of pro-inflammatory stimuli such as TNF- $\alpha$ and IL-1 as well as viral proteins and stress inducers are potent activators [42]. In T-cells, protein kinase $\mathrm{C} \theta$ (PKC $\theta)$ and 
PKC $\alpha$ activate NF- $\mathrm{kB}$ following CD3/CD28 ligation [43-45]. Phorbol ester activation of PKCs can reactivate HIV-1 in cell lines and importantly, in primary quiescent $\mathrm{T}$ cells [46,47]. More recently, members of the LAT signalosome including ADAP have been found to be needed for optimal NF- $\mathrm{kB}$ activation $[41,48]$. However, given the different members of the NF- $\kappa B$ family that can be affected by upstream mediators, it has been unclear whether ADAP is needed for HIV-1 LTR transcription. Our findings showed a significant loss of antiCD3/CD28 induced HIV-1 transcripts in JDAP cells, indicating that ADAP is needed for LTR activation. This in turn was reflected by a lack of detectable IkB $\alpha$ degradation in ADAP deficient JDAP cells. This regulatory event was linked further upstream to SLP-76, since a loss of binding to SLP-76 by the M12 mutant impaired LTR activity in Jurkat and primary human T-cells. It is important to note that overexpression of SLP-76 into JDAP cells did not rescue the defective HIV-1 LTR transcription. This observation suggests that ADAP is the downstream effector of SLP-76 to regulate HIV-1 transcription. Overexpression of SLP-76 increased HIV-1 LTR transcription in WT and SLP-76 deficient J14 Jurkat cells. This effect of SLP-76 on transcription differs from a previous study [49]. The basis of this difference is unclear; however, different results might be caused by different methods used in these studies. Those authors examined the amount of full-length or sliced HIV transcripts by qRT-PCR after J14 or wild type cells were infected with HIV-1 IIIB virus. We used anti-CD3/CD28 to activate J14 or wild type cells and the readout was based on the HIV LTR luciferase reporter assay. The dependency of NF-kB activation on CD28 expression and its engagement in our studies might explain the differences in results. In either case, our findings are consistent with a scenario of SLP-76 upstream regulation of $\mathrm{ADAP}$ that in turn is the effector in the regulation of $\mathrm{NF}-\kappa \mathrm{B}$ transcription.

Further, we observed that the inhibition of Src kinase and PLC $\gamma 1$ activity blocked ADAP potentiation of HIV-1 LTR transcription in response to anti-CD3/CD28 stimulation. This finding is consistent with the observation that $\mathrm{p} 59^{\mathrm{fyn}}$ can bind and phosphorylate ADAP, while $\mathrm{p} 56^{\text {lck }}$ is potentially involved in NF- $\mathrm{kB}$ activation [50]. Consistent with other reports, PLC $\gamma 1$ activity is required in guanine nucleotide exchange factor Vav-1 induced activation of NF-kB [51]. Overall, our data indicate for the first time that ADAP and SLP-76 are needed for anti-CD3/CD28-induced NF- $\mathrm{BB}$ binding to the HIV-1 LTR and optimal HIV-1 transcription.

Our second major observation was that ADAP regulated HIV-1 transmission between DC-T or T-T cells. Evidence has accumulated over the years showing efficient viral spread by direct cell-cell contact [52]. In our study, while the blocking of LFA-1 had no effect on the NF-kB-driven HIV-1 LTR transcription, it nevertheless effectively impaired HIV-1 infection. This observation underscored the distinct nature of the two steps affected by ADAP. JDAP cells and human primary $\mathrm{CD}^{+}{ }^{+} \mathrm{T}$ cells with reduced ADAP expression by siRNA formed markedly reduced numbers of T-DC conjugates and showed decreased HIV-1-GFP VLP localization at the VS interface. We observed that the M12 mutant also inhibited $\mathrm{T}$-T conjugate formation, while the remaining conjugates showed a reduced size of the interface at VS. Both events would be expected to interfere with the optimal viral spread between cells. Finally, in agreement, the de novo HIV DNA synthesis as measured by levels of HIV pol in T-cell cultures confirmed a significant reduction in viral spread.

The identity of other signaling mediators other than src kinases and phospholipase $\mathrm{C}$ that cooperate with ADAP to regulate the VS formation and cell-to-cell viral spread remains to be determined. ITK and ZAP-70 are needed for viral cell-cell transmission [53,54], whereas ADAP has additional binding sites for vasodilatorstimulated phosphoprotein (VASP), a regulator of actin branching [55]. LFA-1 ligation can re-model actin in T-cells [31,56,57] and $\mathrm{T}$ cells require actin polymerization for HIV-1polarization at the cell-cell contact area. This in turn is needed for the proper formation of the VS between T-cells, as well as the efficient entry of HIV-1 into activated CD $4^{+} \mathrm{T}$ cells [57]. In agreement, we observed reduced cell spreading in JDAP cells, as well as a reduced interface between HIV-1 infected $\mathrm{T}$ cells and non-infected M12 cells. The inside-out pathway is linked ADAP with the downstream SKAP-1, which is needed for the RapL-Rap1 complex formation and binding of this complex to the cytoplasmic tail of LFA-1 [32,33,35,36,58]. In this context, LFA-1 also determines the preferential infection of memory $\mathrm{CD}_{4}^{+}$ T cells by HIV-1 [59]. Together, ADAP and the SLP76-ADAP complex represent exciting novel targets for reducing two steps of HIV-1 infection.

\section{Conclusion}

This study is the first reported demonstration that ADAP and the SLP-76/ADAP signaling module play central roles in two distinct phases of HIV-1 infection. Firstly, ADAP cooperated with the co-receptor CD28 and TCR to enhance HIV-1 LTR transcription via the regulation of NF- $\mathrm{kB}$. This regulatory event was dependent on expression of co-receptor CD28, as well as the activity of src kinases and phospholipase C. Phosphoinositol 3-kinase (PI $3 \mathrm{~K}$ ) and LFA-1 were not needed for ADAP regulation of HIV-1 LTR transcription. By contrast, SLP-76/ADAP regulation of viral cell-cell spread was reflected by a reduction in LFA-1-dependent DC-T or T-T cell 
conjugation by the absence of ADAP or expression of M12, as well as well as impaired formation of the VS between cells. Overall, our evidence shows that ADAP and its binding to SLP-76 regulates propagation of HIV-1 by two distinct coreceptors, and identifies the immune adaptor ADAP as a new possible target to control HIV-1 infection.

\section{Methods}

Cells

ADAP or M12 was subcloned into the retroviral vector pMXF5 containing IRES-GFP, and these plasmids were transfected in $293 \mathrm{~T}$ cells to prepare retroviral supernatants. Human C8166 and Jurkat T cells were transduced with these retroviral supernatants, and $\mathrm{GFP}^{+}$cells were sorted by flow cytometry, which could stably express GFP vector or ADAP/GFP or M12/GFP. C8166 cells, Jurkat T cells, J14 (SLP-76 deficient) cells and JDAP (ADAP deficient) cells (a kind gift from Dr. Y. Huang, National Institutes of Health, Intramural Research Program/Department of Health and Human Services, Baltimore, Maryland, USA) were cultured in RPMI 1640 medium supplemented with $10 \%(\mathrm{v} / \mathrm{v})$ fetal bovine serum (FBS), $100 \mathrm{U} / \mathrm{ml}$ penicillin, $100 \mu \mathrm{g} / \mathrm{mL}$ streptomycin at $37^{\circ} \mathrm{C}$ and $5 \% \mathrm{CO}_{2}$. CD14 monocytes were purified from human PBMCs (human peripheral blood mononuclear cells) using anti-CD14 antibodies-coated magnetic beads (BD Biosciences) and cultured with $50 \mathrm{ng} / \mathrm{ml}$ of granulocyte-macrophage colony stimulating factor (GM-CSF) (R\&D) and IL-4 (R\&D) for 6 days to generate immature DCs. Immature DCs were stimulated with LPS $(10 \mathrm{ng} / \mathrm{ml})$ for $48 \mathrm{~h}$ to generate mature DCs. Primary CD4 $4^{+}$T cells were purified from human PBMCs using anti-CD4 antibodies-coated magnetic beads (BD Biosciences) and activated with $5 \mu \mathrm{g} / \mathrm{mL}$ of phytohemagglutinin-P (PHA-P) (Sigma-Aldrich) for $72 \mathrm{~h}$ in the presence of $20 \mathrm{IU} / \mathrm{mL}$ of recombinant IL-2 (R\&D).

\section{CA-p24 ELISA assay}

To measure HIV-1 p24 ${ }^{\mathrm{Gag}}$ levels in the culture medium, culture supernatant was firstly heat inactivated at $56^{\circ} \mathrm{C}$ for $30 \mathrm{~min}$ in the presence of $0.05 \%$ Empigen-BB (Calbiochem, La Jolla, USA) and the CA-p24 concentration was determined by ELISA with D7320 (Biochrom, Berlin, Germany) as the capture antibody and alkaline phosphatase-conjugated anti-p24 monoclonal antibody (EH12-AP) as the detection antibody using a lumiphos plus system (Lumigen, Michigan, USA) in a LUMIstar Galaxy luminescence reader (BMG labtechnologies, Offenburg, Germany).

\section{HIV LTR driven transcription by luciferase assay}

The pLTR-gag3-flag-luc plasmid contains the HIV-1 5' LTR promoter region, the complete leader RNA, the Nterminal three Gag amino acids followed by the Flag peptide (amino acids DYKDDDDKD) and the firefly luciferase protein. The pLTR-gag3-flag-luc plasmid was transfected in Jurkat cells together with plasmids expressing ADAP/GFP, M12/GFP or GFP alone. Transfected cells were then seeded on to anti-CD3 and antiCD28 or purified B7.1-Fc coated plate for 6 hrs. Cells were then harvested, lysed and measured for luciferase activity according to the protocol provided by Promega kits. Alternatively, transfected cells were treated with src kinase inhibitor PP2, PI3K inhibitor LY294002, PLC $\gamma$ inhibitor U73122 or anti-LFA1 antibody (i.e. antiCD18) over the incubation period.

\section{Knockdown of ADAP expression by siRNA}

Specific siRNAs targeting human ADAP (5'-CCUGGU GAAUCUCUAGAAGTT-3') or scrambled control siRNAs were transfected into human primary $\mathrm{CD}^{+}$cells using Lipofectamine 2000 (Invitrogen) as directed by the manufacturer. The levels of ADAP expression were examined by Western blotting at $48 \mathrm{~h}$ after transfection or by qRT-PCR at various time points.

\section{Immunoprecipitation, immunoblotting and EMSA assay}

To check the activity of NF- $k B$, Jurkat and JDAP cells or C8166 cells over-expressing ADAP/GFP, M12/GFP and GFP control were stimulated with anti-CD3 $(1 \mu \mathrm{g} / \mathrm{ml})$ and anti-CD28 $(2 \mu \mathrm{g} / \mathrm{ml})$ antibodies for $30 \mathrm{~min}$ or indicated time. Nuclear extracts were prepared and incubated with biotin labelled NF- $\mathrm{NB}$ probes. Activated NF- $\kappa B$ formed a complex with NF- $\kappa B$ probes that could be detected according to Panomics's protocol. Alternatively, cell lysates were prepared for immunoblotting with $I_{\kappa} B \alpha$ and actin to detect the degradation of $I_{\kappa} B \alpha$.

\section{HIV-1 stocks and viral-like particles (VLPs)}

CXCR4-tropic HIV-1 virus (pNL4.3) was generated by transfecting 293T cells as described below and infectivity determined by luciferase assay on HeLa tzmbl cells. HIV-1 viral stocks produced in C33A cells (24 wells plate) were produced by transfection of $1 \mu \mathrm{g}$ of pLAI-R37. Pseudotyped single-cycle, luciferase reporter HIV stocks, HIV-Luc/NL4-3, were generated by calcium phosphate-mediated cotransfections of HEK293T cells with pLAI- $\Delta$ env-Luc, an env-deleted and nef-inactived HIV-1 proviral construct, and a construct expressing for HIV envelope protein (Env) of NL4-3 (X4-tropic) as described previously [12]. To produce HIV-1 VLPs, HIV-1-gag-GFP/NL4-3, were generated by cotransfection of HEK293T cells with a plasmid encoding HIVgag-GFP and with an expression plasmid of NL4-3 Env. Supernatants that contain HIV-1 particles were harvested, filtered and titrated with p24 ${ }^{\text {Gag }}$ capture ELISA. 


\section{Virus infection and replication}

Human primary $\mathrm{CD}^{+}{ }^{+} \mathrm{T}$ cells knocking down of ADAP; C8166 cells and Jurkat cells stably overexpressing GFP or ADAP/GFP or M12/GFP; J14, JDAP or wild type Jurkat cells were respectively incubated with single-cycle HIV stocks (i.e. HIV-Luc/NL4-3 containing luciferase reporter, $1 \mathrm{ng}$ or $5 \mathrm{ng}$ of $\mathrm{p} 24^{\mathrm{Gag}}$ ) for $2 \mathrm{~h}$ at $37^{\circ} \mathrm{C}$. After washing of excessive HIV-1 viruses, the above cells were incubated for further 3 days [12]. Alternatively, anti-LFA-1 or soluble ICAM-1-Fc was used to pre-treat $\mathrm{T}$ cells for $15 \mathrm{~min}$ and was kept in the culture medium during the incubation time. Cells were washed intensively post-infection and cell lysates were prepared to measure luciferase activity with a kit from Promega. Or, the amount of viruses was quantified by detecting HIV1-gag mRNA levels with qRT-PCR using the forward primer (5'-GTGTGGAAAATCTCT AGCAGTGG-3') and the reverse primer (5'-CGCTCTCGCACCCATCTC-3'). Actin was used as an internal reference.

\section{HIV-1 infection and transmission between T-T cells}

$\mathrm{T}$ cells were infected with HIV-1 strain pNL4-3 by spinoculation and cells were cultured for 3 days before being used as HIV $-1^{+}$donor cells. $5 \times 10^{5} \mathrm{ADAP} / \mathrm{GFP}$ or M12/ GFP expressing target cells were mixed with $2.5 \times 10^{5}$ HIV + donor T cells, incubated for 0, 6, 12 and $24 \mathrm{hr}$, and genomic DNA was extracted (Qiagen). Quantitative realtime PCR was performed to measure HIV pol DNA and the house-keeping gene albumin as described previously $[10,13,14]$ The ratio of HIV pol DNA to albumin was determined as the HIV DNA copy number and the fold increase was calculated relative to the amount of HIV-1 DNA at the time point $0 \mathrm{hr}$ as a measure of cell-cell spread.

\section{Conjugate or VS formation and immunostaining}

For T-T conjugation, $5 \times 10^{5} \mathrm{HIV}^{+}$donor cells were mixed with an equal number of target cells at $37^{\circ} \mathrm{C}$ on poly-L-lysine-treated coverslips for up to $1 \mathrm{hr}$ as described previously [11]. Conjugates were fixed in $4 \%$ formaldehyde and permeabilized in $0.1 \%$ Triton X-100/5\% FCS. Immunostaining of conjugates was performed using the following reagents: phalloidin-TRITC (Sigma-Aldrich), anti-Env mAb (mAb 50-69, donated by S. Zoller-Pazner and obtained from the CFAR, NIBSC, UK), rabbit antisera against HIV-1 Gag p17 and p24 (donated by G. Reid and obtained from the CFAR, NIBSC UK). To form DC-T conjugation, mature DCs $\left(2 \times 10^{5}\right.$ cells $)$ were preincubated with HIV-1-p24 ${ }^{\text {Gag }}$-GFP/NL4-3 VLPs (20 ng of p24) at $37^{\circ} \mathrm{C}$ for $2 \mathrm{hr}$ as previously described [12]. After extensive washes, these DCs were then incubated for $30 \mathrm{~min}$ at a ratio of 1:1 with Jurkat cells overexpressing ADAP/GFP or M12/GFP; J14 or JDAP; human primary $\mathrm{CD} 4^{+} \mathrm{T}$ cells knocking down of ADAP; and the control cells respectively. Conjugates were stained with anti-LFA-1 or anti-ADAP (BD Bioscience). Stained coverslips were mounted in Molwiol 4-88 (Calbiochem) or Prolong Gold antifade (Invitrogen), and analyzed using a confocal microscope linked to LSM $510^{\text {ma }}$ software (Carl Zeiss MicroImaging, Inc.) or a Leica SP2.

\section{Statistics analysis}

Data are presented as mean \pm SEM. A two-tailed Student's t-test was used to compare two groups. ANOVA was used to analyze difference among three groups. For all test, a $\mathrm{P}$ value of 0.05 or less was considered statistically significant.

\section{Additional files}

\begin{abstract}
Additional file 1: Figure S1. (A) After HIV-1 infection, Jurkat cells overexpressing GFP, ADAP/GFP or M12/GFP expressed surface CD4 and CXCR4 at the same levels. (B) C8166 T cells were stably transduced with GFP, ADAP/GFP or M12/GFP. The transduced efficiency reached over $95 \%$ according to the percent of GFP + cells by flow cytometry (left panel), and the expression levels of ADAP or M12 were assessed by immunoblotting (middle panel). These cells were infected with low or high doses (equivalent to 1.5 or 15 ng p24 ${ }^{\mathrm{Gag}}$, respectively) of HIV-1, and supernatants were collected at various times post infection to check the presence of p24 ${ }^{\text {Gag }}$ by ELISA (right panel). Two independent experiments were performed and the representative data were collected from triplicate samples with error bars. (C) ADAP or M12 expression in C8166 cells did not affect the surface expression levels of CD4, CXCR4, CD3, CD28, $\beta 1$ integrin or ICAM-1 as determined by flow cytometry. (D) Overexpression of ADAP or M12 in C8166 cells did not significantly alter cell proliferative capacity. (E) Knockdown of ADAP in human primary CD4 ${ }^{+} T$ cells did not alter the surface expression levels of CD4, CXCR4, CD3, CD28, $\beta 1$ or $\beta 2$ integrins and ICAM-1.

Additional file 2: Figure S2. The reporter plasmid pLTR-gag3-flag-luc contains the HIV-1 5' LTR promoter region, three amino acids of Gag, the Flag tag, followed by the firefly luciferase open reading frame. (A) ADAP was cotransfected into Jurkat cells with the report plasmids expressing wild type HIV-1 LTR or the mutant LTR which lost NFB binding sites. The cells were then stimulated with anti-CD3/CD28 for 6 hrs to measure the luciferase readings. (B) Src kinase and $\mathrm{PLC} \gamma$, but not $\mathrm{PI} 3 \mathrm{~K}$, is essential for anti-CD3/ CD28-induced HIV-1 transcription. Jurkat cells expressing GFP or ADAP/GFP were treated with specific inhibitors or anti-CD18, followed by a measurement of HIV-1 LTR transcription. Three independent experiments were performed and the representative data were collected from triplicate samples with error bars (* represents $p=<0.05$, ${ }^{* *}$ represents $p=<0.001$ ).

Additional file 3: Figure S3. (A) The surface expression levels of $\beta 2$ integrin (i.e. CD18) on Jurkat and $J 14$ cells were determined by flow cytometry. (B) Jurkat and JDAP cells were stimulated with plate-coated anti-CD3 and ICAM-1 $(P=0.0001)$. F-actin was stained with PhalloidinTRITC to observe cell spreading.
\end{abstract}

\section{Competing interests}

We submit it as a regular article. All the authors concur with the submission. All the funding bodies and their recipients have been listed. All the data were generated by the current authors. This work has not been published elsewhere. We don't have any financial or commercial conflicts of interests.

\section{Authors' contributions}

BW, LH, TA, EG, CJ, DL, RT, WG, HW performed experiments and statistical analysis. HW, CER, BW, CJ, JW participated in the design of the study. HW CER, BW drafted the manuscript. TA, AL, CJ, JW, RZ provided viruses, cells, coordinate and helped to draft the manuscript. All authors read and approved the manuscript. 


\section{Acknowledgements}

HW was funded by the Ministry of Science and Technology China (2012CB910800), National Natural Science Foundation of China (31370859, 31070778), Pujiang Program (2010-0000506), Key lab of Molecular Virology \& Immunology in CAS. CER was funded by a grant from the Wellcome Trust. CJ was supported by a Medical Research Council Career Development Award (G0800312). TEMA was supported by an intra-European Marie Curie fellowship (220092).

\section{Author details}

${ }^{1}$ The State Key Laboratory of Cell Biology, Institute of Biochemistry and Cell Biology, Shanghai Institutes for Biological Sciences, Chinese Academy of Sciences, Shanghai, China. 'Department of Medicine, Level 5, Addenbrooke's Hospital, Hills Road, Cambridge CB2 2QQ, UK. ${ }^{3}$ Division of Infection and Immunity, University College London, London WC1E 6BT, UK. ${ }^{4}$ Cell Signalling Section, Division of Immunology, Department of Pathology, Tennis Court Road, University of Cambridge, Cambridge CB2 1QP, UK. ${ }^{5}$ Institute Pasteur of Shanghai, Chinese Academy of Science, Shanghai, China. ${ }^{6}$ Cambridge Institute of Medical Research, Hills Road, CB2 OXY, Cambridge, UK. ${ }^{7}$ TEMA current address: Centre for Childhood White Matter Disorders, VU University Medical Centre, De Boelelaan 1087, 1081HV, Amsterdam, the Netherlands.

Received: 9 April 2013 Accepted: 12 September 2013

Published: 18 September 2013

\section{References}

1. Letvin NLBD, Montefiori DC: Prospects for vaccine protection against HIV-1 infection and AIDS. Annu Rev Immunol 2002, 20:73-99.

2. McMichael AJ: HIV vaccines. Annu Rev Immunol 2006, 24:227-255.

3. Kinoshita S, Su L, Amano M, Timmerman LA, Kaneshima H, Nolan GP. The T cell activation factor NF-ATc positively regulates HIV-1 replication and gene expression in T cells. Immunity 1997, 6:235-244

4. Imbeault M, Giquère $K$, Ouellet $M$, Tremblay MJ: Exon level transcriptomic profiling of HIV-1-infected CD4 (+) T cells reveals virus-induced genes and host environment favorable for viral replication. PLoS Pathog 2012, 8:e1002861.

5. Kwon HPN, DeLuca C, Genin P, Cisternas S, Lin R, Wainberg MA, Hiscott J. Inducible expression of IkappaBalpha repressor mutants interferes with NF-kappaB activity and HIV-1 replication in Jurkat T cells. J Biol Chem 1998, 273(13):7431-7440.

6. Nabel G, Baltimore D: An inducible transcription factor activates expression of human immunodeficiency virus in T cells. Nature 1987, 326(6114):711-713

7. Nabel GJ, Rice SA, Knipe DM, Baltimore D: Alternative mechanisms for activation of human immunodeficiency virus enhancer in T cells. Science 1988, 239:1299-1302.

8. Berkhout B, Jeang KT: Functional roles for the TATA promoter and enhancers in basal and Tat-induced expression of the human immunodeficiency virus type 1 long terminal repeat. J Virol 1992, 66:139-149.

9. Sowinski S, Jolly C, Berninghausen O, Purbhoo MA, et al: Membrane nanotubes physically connect $T$ cells over long distances presenting a novel route for HIV-1 transmission. Nat Cell Biol 2008, 10:211-219.

10. Martin N, Welsch S, Jolly C, Briggs JA, Vaux D, et al: Virological synapse-mediated spread of human immunodeficiency virus type 1 between T cells is sensitive to entry inhibition. J Virol 2010, 84:3516-3527.

11. Jolly C, Kashefi K, Hollinshead M, Sattentau QJ: HIV-1 cell to cell transfer across an Env-induced, actin-dependent synapse. J Exp Med 2004, 199(2):283-293.

12. Wang JH, Kwas C, Wu L: Intercellular adhesion molecules (ICAM)-1, but not ICAM-2 and -3 , is important for dendritic cell-mediated human immunodeficiency virus type 1 transmission. J Virol 2009, 83:4195-4204.

13. Jolly C, Booth NJ, Neil SJ: Cell-cell spread of human immunodeficiency virus type 1 overcomes tetherin/BST-2-mediated restriction in T cells. J Virol 2010, 84(23):12185-12199.

14. Jolly C, Welsch S, Michor S, Sattentau QJ: The regulated secretory pathway in CD4 (+) T cells contributes to human immunodeficiency virus type- 1 cell-to-cell spread at the virological synapse. PLoS Pathog 2011 7(9):1002226.

15. Hubner W, McNerney GP, Chen P, Dale BM, Gordon RE, Chuang FY, Li XD, Asmuth DM, Huser T, Chen BK: Quantitative 3D video microscopy of HIV transfer across T cell virological synapses. Science 2009, 323(5922):1743-1747.

16. Groot F, Welsch S, Sattentau QJ: Efficient HIV-1 transmission from macrophages to T cells across transient virological synapses. Blood 2008, 111:4660-4663.

17. Chen P, Hübner W, Spinelli MA, Chen BK: Predominant mode of human immunodeficiency virus transfer between T cells is mediated by sustained Env-dependent neutralization-resistant virological synapses. J Virol 2007, 81(22):12582-12595.

18. Brenchley JM, Schacker TW, Ruff LE, Price DA, Taylor JH, Beilman GJ, Nguyen PL, Khoruts A, Larson M, Haase AT, et al: CD4+ T cell depletion during all stages of HIV disease occurs predominantly in the gastrointestinal tract. J Exp Med 2004, 200(6):749-759.

19. Arrighi JF, Pion M, Garcia E, Escola JM, van Kooyk Y, Geijtenbeek TB, Piguet V: DC-SIGN-mediated infectious synapse formation enhances X4 HIV-1 transmission from dendritic cells to T cells. J Exp Med 2004, 200(10):1279-1288

20. McDonald D, Wu L, Bohks SM, KewalRamani VN, Unutmaz D, Hope TJ: Recruitment of HIV and its receptors to dendritic cell-T cell junctions. Science 2003, 300(5623):1295-1297.

21. Groot F, Kuijpers T, Berkhout B, de Jong EC: Dendritic cell-mediated HIV-1 transmission to T cells of LAD-1 patients is impaired due to the defect in LFA-1. Retrovirology 2006, 3:75.

22. Hioe CE, Bastiani L, Hildreth JE, Zolla-Pazner S: Role of cellular adhesion molecules in HIV type 1 infection and their impact on virus neutralization. AIDS Res Hum Retroviruses 1998, 3(14):S247-54

23. Bounou S, Leclerc JE, Tremblay MJ: Presence of host ICAM-1 in laboratory and clinical strains of human immunodeficiency virus type 1 increases virus infectivity and CD4 (+)-T-cell depletion in human lymphoid tissue, a major site of replication in vivo. J Virol 2002, 76:1004-1014.

24. Stevenson M, Stanwick TL, Dempsey MP, Lamonica CA: HIV-1 replication is controlled at the level of T cell activation and proviral integration. EMBO J 1990, 9:1551-1560

25. Jordan MS, Singer AL, Koretzky GA: Adaptors as central mediators of signal transduction in immune cells. Nat Immunol 2003, 4(2):110-116.

26. Wang H, Rudd CE: SKAP-55, SKAP-55-related and ADAP adaptors modulate integrin-mediated immune-cell adhesion. Trends Cell Biol 2008, 18(10):486-493.

27. Sommers CL, Samelson LE, Love PE: LAT: a T lymphocyte adapter protein that couples the antigen receptor to downstream signaling pathways. Bioessays 2004, 26(1):61-67.

28. Yablonski D, Weiss A: Mechanisms of signaling by the hematopoietic-specific adaptor proteins, SLP-76 and LAT and their B cell counterpart, BLNK/SLP-65. Adv Immunol 2001, 79:93-128.

29. Musci MA, Hendricks-Taylor LR, Motto DG, Paskind M, Kamens J, Turck CW, Koretzky GA: Molecular cloning of SLAP-130, an SLP-76-associated substrate of the $T$ cell antigen receptor-stimulated protein tyrosine kinases. J Biol Chem 1997, 272(18):11674-11677.

30. da Silva AJ, Li Z, de Vera C, Canto E, Findell P, Rudd CE: Cloning of a novel T-cell protein FYB that binds FYN and $\mathrm{SH}$ 2-domain-containing leukocyte protein 76 and modulates interleukin 2 production. Proc Natl Acad SCi USA 1997, 94(14):7493-7498.

31. Wang H, Wei B, Bismuth G, Rudd CE: SLP-76-ADAP adaptor module regulates LFA-1 mediated costimulation and T cell motility. Proc Natl Acad Sci USA 2009, 106(30):12436-12441.

32. Kliche S, Breitling D, Togni M, Pusch R, Heuer $K$, et al: The ADAP/SKAP55 signaling module regulates $T$-cell receptor-mediated integrin activation through plasma membrane targeting of Rap1. Mol Cell Biol 2006, 26:7130-7144

33. Wang H, Liu H, Lu Y, Lovatt M, Wei B, Rudd CE: Functional defects of SKAP-55 deficient T-cells identify a regulatory role for the adaptor in LFA-1 adhesion. Mol Cell Biol 2007, 27(19):6863-6875.

34. Wang H, McCann FE, Gordan JD, Wu X, Raab M, Malik TH, Davis DM, CE R: ADAP-SLP-76 binding differentially regulates supramolecular activation cluster (SMAC) formation relative to T cell-APC conjugation. J Exp Med 2004, 200(8):1063-1074.

35. Wang H, Moon EY, Azouz A, Wu X, Smith A, Schneider H, Hogg N, Rudd CE: SKAP-55 regulates integrin adhesion and formation of T cell-APC conjugates. Nat Immunol 2003, 4(4):366-374.

36. Raab M, Wang H, Lu Y, Smith X, Wu Z, Strebhardt K, Ladbury JE, Rudd CE: T cell receptor "inside-out" pathway via signaling module SKAP1-RapL 
regulates T cell motility and interactions in lymph nodes. Immunity 2010, 32(4):541-556.

37. Huang $Y$, Norton DD, Precht $P$, Martindale JL, Burkhardt JK, Wange RL: Deficiency of ADAP/Fyb/SLAP-130 destabilizes SKAP55 in Jurkat T cells. J Biol Chem 2005, 280(25):23576-23583.

38. Abbink TE, Berkhout B: RNA structure modulates splicing efficiency at the human immunodeficiency virus type 1 major splice donor. J Virol 2008, 82(6):3090-3098

39. Baltimore D: NF-kappaB is 25. Nat Immunol 2011, 12(8):683-685.

40. Raab M, Smith X, Matthes Y, Strebhardt K, Rudd CE: SKAP1 PH domain determines RAPL membrane localization and Rap1 complex formation for TCR activation of LFA-1. J Biol Chem 2011, 286:29663-29670.

41. Medeiros RB, Burbach BJ, Mueller KL, Srivastava R, Moon JJ, et al: Regulation of NF-kappaB activation in T cells via association of the adapter proteins ADAP and CARMA1. Science 2007, 316:754-758.

42. Li Q, Verma IM: NF-kappaB regulation in the immune system. Nat Rev Immunol 2002, 2:725-734.

43. Lin X, O'Mahony A, Mu Y, Geleziunas R, Greene WC: Protein kinase C-theta participates in NF-kappaB activation induced by CD3-CD28 costimulation through selective activation of lkappaB kinase beta. Mol Cell Biol 2000, 20:2933-2940.

44. Coudronniere N, Villalba M, Englund N, Altman A: NF-kappa B activation induced by $T$ cell receptor/CD28 costimulation is mediated by protein kinase C-theta. Proc Natl Acad Sci USA 2000, 97:3394-3399.

45. Trushin SA, Pennington KN, Carmona EM, Asin S, Savoy DN, Billadeau DD, Paya CV: Protein kinase Calpha (PKCalpha) acts upstream of PKCtheta to activate IkappaB kinase and NF-kappaB in T lymphocytes. Mol Cell Biol 2003, 23(19):7068-7081.

46. Adams M, Sharmeen L, Kimpton J, Romeo JM, Garcia JV, Peterlin BM, Groudine M, Emerman M: Cellular latency in human immunodeficiency virus-infected individuals with high CD4 levels can be detected by the presence of promoter-proximal transcripts. Proc Natl Acad Sci USA 1994, 91(9):3862-3866

47. Brooks DG, Arlen PA, Gao L, Kitchen CM, Zack JA: Identification of T cell-signaling pathways that stimulate latent HIV in primary cells. Proc Natl Acad Sci USA 2003, 100(22):12955-12960.

48. Srivastava R, Burbach BJ, Shimizu Y: NF-kappaB activation in T cells requires discrete control of IkappaB kinase alpha/beta (IKKalpha/beta) phosphorylation and IKKgamma ubiquitination by the ADAP adapter protein. J Biol Chem 2010, 285:11100-11105.

49. Nagaraja T, Anand AR, Zhao H, Ganju RK: The adaptor protein SLP-76 regulates HIV-1 release and cell-to-cell transmission in T cells. J Immunol 2012, 188:2769-2777.

50. Briant L, Robert-Hebmann V, Acquaviva C, Pelchen-Matthews A, Marsh M, Devaux C: The protein tyrosine kinase p56lck is required for triggering NF-kappaB activation upon interaction of human immunodeficiency virus type 1 envelope glycoprotein gp120 with cell surface CD4. J Virol 1998, 72(7):6207-6214.

51. Dienz O, Möller A, Strecker A, Stephan N, Krammer PH, Dröge W, Schmitz ML: Src homology 2 domain-containing leukocyte phosphoprotein of 76 $\mathrm{kDa}$ and phospholipase C gamma 1 are required for NF-kappa B activation and lipid raft recruitment of protein kinase $C$ theta induced by T cell costimulation. J Immunol 2003, 170(1):365-372.

52. Sattentau Q: Avoiding the void: cell-to-cell spread of human viruses. Nat Rev Microbiol 2008, 6(11):815-826.

53. Readinger JA, Schiralli GM, Jiang JK, Thomas CJ, August A, et al: Selective targeting of ITK blocks multiple steps of HIV replication. Proc Natl Acad Sci USA 2008, 105:6684-6689.

54. Sol-Foulon N, Sourisseau M, Porrot F, Thoulouze MI, Trouillet C, et al: ZAP-70 kinase regulates HIV cell-to-cell spread and virological synapse formation. EMBO J 2007, 26:516-526.

55. Krause M, Sechi AS, Konradt M, Monner D, Gertler FB, Wehland J: Fyn-binding protein (Fyb)/SLP-76-associated protein (SLAP), Ena/ vasodilator-stimulated phosphoprotein (VASP) proteins and the Arp2/3 complex link T cell receptor (TCR) signaling to the actin cytoskeleton. J Cell Biol 2000, 149(1):181-194.

56. Suzuki J, Yamasaki S, Wu J, Koretzky GA, Saito T: The actin cloud induced by LFA-1-mediated outside-in signals lowers the threshold for T-cell activation. Blood 2007, 109(1):168-175.
57. Vasiliver-Shamis G, Cho MW, Hioe CE, Dustin ML: HIV-1 envelope gp120induced partial T-cell receptor signaling creates an F-actin-depleted zone in the virological synapse. J Virol 2009, 83:11341-11355.

58. Katagiri K, Maeda A, Shimonaka M, Kinashi T: RAPL, a Rap1-binding molecule that mediates Rap1-induced adhesion through spatial regulation of LFA-1. Nat Immunol 2003, 4(8):741-748.

59. Tardif MR, Tremblay MJ: LFA-1 is a key determinant for preferential infection of memory CD4+ T cells by human immunodeficiency virus type 1. J Virol 2005, 79:13714-13724.

doi:10.1186/1742-4690-10-101

Cite this article as: Wei et al:: Immune adaptor ADAP in T cells regulates HIV-1 transcription and cell-cell viral spread via different co-receptors. Retrovirology 2013 10:101.

\section{Submit your next manuscript to BioMed Central and take full advantage of:}

- Convenient online submission

- Thorough peer review

- No space constraints or color figure charges

- Immediate publication on acceptance

- Inclusion in PubMed, CAS, Scopus and Google Scholar

- Research which is freely available for redistribution 